Recife, Volume 9, 2020 (85-100)

https://doi.org/10.46802/rmsde.v9i2.247737

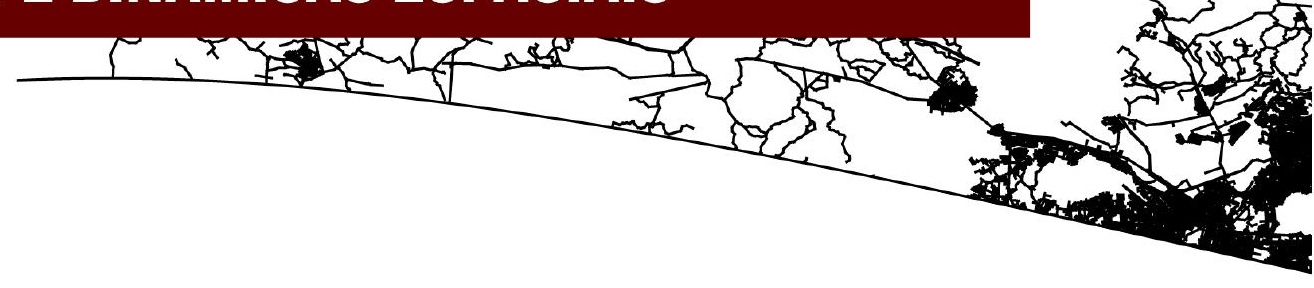

\title{
OS VETORES PRAIANOS NA PRODUÇÃO DO ESPAÇO METROPOLITANO DO RECIFE
}

\author{
BEACH VECTORS IN THE PRODUCTION OF \\ METROPOLITAN SPACE, RECIFE, BRAZIL
}

Otávio Augusto Alves dos SANTOS ${ }^{1}$

Artigo recebido em 04/08/2020, aceito em 26/12/2020, publicado em 28/12/2020.

Palavras-chave: Vetores; Espaço metropolitano; Praias do Recife

Keywords:

Vectors; Metropolitan space; Beaches of Recife

\section{RESUMO}

Este trabalho procura refletir sobre a praia como vetor da produção do espaço metropolitano, dando ênfase ao processo de urbanização litorânea do Recife. A hipótese é a de que essas praias foram apropriadas inicialmente e transformadas em vetores, que indicavam tanto 0 sentido da urbanização, quanto seu veículo, fomentando processos de valorização e consumo do espaço. Na tentativa de responder, recorre-se ao método histórico-dialético, tendo como procedimento: o levantamento bibliográfico sobre 0 processo de urbanização litorânea no Nordeste do Brasil; análise de dados sobre crescimento urbano metropolitano, atividades turísticas e investimentos públicos em infraestrutura; além de visitas in situ e reflexão crítica. Ao final, conclui-se que as praias do Recife têm sido, desde o início do séc. XX, 0 ambiente por onde a cidade vem crescendo, interligando-se com outros núcleos urbanos e, consequentemente, criando sua região metropolitana.

\section{ABSTRACT}

This work seeks to reflect on how the beach can be a vector for the production of the metropolitan space, emphasizing the process of coastal urbanization in Recife, Brazil. The hypothesis is that these beaches were initially appropriated and transformed in vectors, indicating both the direction of the urbanization and its role as vehicle, promoting processes of valorization and consumption of space. For this, the historical-dialectical method is used, consisting the concrete procedure in: the bibliographic study of the process of coastal urbanization in northeast Brazil; analysis of data on metropolitan urban growth, tourist activities, and public investments in infrastructure; in situ visits; and critical reflection. In the end, it is concluded that the beaches of Recife have been, since the beginning of the 20th century, the environment where the city has been growing, interconnecting with other urban centers and, consequently, creating its metropolitan region.

\footnotetext{
${ }^{1}$ Professor do Departamento de História da Universidade Federal Rural de Pernambuco. E-mail: otavio.augusto@ufrpe.br
} 


\section{INTRODUÇÃO}

Conceito próprio da física e da geometria, os vetores correspondem a grandezas cuja representação quase sempre é dada por uma reta e uma seta, apontando certa direção. 0 dicionário Houaiss (HOUAISS et al, 2015) define vetor como "segmento orientado de reta". Na biologia e na epidemiologia, contudo, o vetor é geralmente visto como um veículo, seja ambiental ou biológico, por meio do qual infecções e doenças são transmitidas. Para os fins que se propõe este artigo, o termo vetor envolve os dois sentidos. Primeiro dirá respeito à direção adquirida pelo processo de valorização expansiva do espaço, que geralmente parte de regiões mais consolidadas para outras áreas menos transformadas pelo trabalho humano, sem necessariamente coincidir com o sentido centro-periferia. Mas também consideramos vetor as formas espaciais, sejam elas naturais ou criadas pelo homem, que atraem e possibilitam mais valorização, funcionando como fomentador na construção de novos espaços.

Os vetores da produção do espaço urbano brasileiro se modificaram fortemente durante o século XX e início do século XXI. Antes, os interesses propalados por diversos agentes hegemônicos do sistema-mundo preconizavam a industrialização e o crescimento das cidades para além de suas fronteiras originais, levando ao processo de metropolização, para o qual contribuiu enormemente o Estado mediante políticas públicas de habitação nas periferias. Isto é, os vetores apontavam para as áreas rurais e não-infraestruturadas, no contexto de uma urbanização física expansiva. A partir dos anos 1980/90, essa tendência é substituída por processos de desvalorização-revalorização e o reaproveitamento dos espaços urbanos consolidados, seja para a promoção habitacional autosegregada, como para criação de lugares gentrificados e turistificados (SANTOS, 2020). Ainda que um novo movimento expansivo tenha ocorrido no início dos anos 2000 e 2010, com as promoções habitacionais autosegregadas em áreas periféricas, a tendência à reprodução se impõe.

Este trabalho procura refletir sobre a praia como vetor da produção do espaço urbano, dando ênfase ao processo de urbanização litorânea do Recife e de sua região metropolitana. Nossa hipótese é a de que essas praias foram apropriadas inicialmente e transformadas em vetores, que indicavam tanto o sentido da urbanização, quanto seu veículo, fomentando processos de valorização e consumo do espaço. Para tanto, recorremos ao método histórico-dialético, tendo como procedimento: o levantamento bibliográfico sobre 0 processo de urbanização litorânea no Nordeste do Brasil; a análise de dados sobre crescimento urbano metropolitano, atividades turísticas e investimentos públicos em infraestrutura; além de visitas in situ e reflexão crítica.

No primeiro item, procuramos refletir sobre como a praia se tornou um vetor (nos dois sentidos aqui trabalhados) do processo de produção do espaço no mundo ocidental, destacando as mudanças de significado social que este ambiente adquiriu no Brasil e no Nordeste no transcurso do século XX. Em seguida, no segundo item, buscamos esclarecer o que vimos chamando de "espaço praiano" para, depois, 
discutir sua produção no Brasil, realçando as especificidades da região Nordeste. Por fim, refletimos sobre 0 papel das praias como vetor na produção do espaço metropolitano do Recife..

\section{A PRAIA COMO VETOR}

As praias são ambientes historicamente criados, podendo ser vistos como resultado de diferentes e conflituosas práticas e representações sociais, a maioria das quais surgidas na realidade europeia de séculos passados, mas absorvidas aqui diferencialmente mediante incorporação de comportamentos e estilos de vida desde cedo vistos como requisitos para o ingresso de determinadas classes na moderno-ocidentalidade (DANTAS, 2009). Devemos a Corbin (1989), o entendimento dessas mudanças na realidade europeia. Segundo este historiador francês, a invenção das praias e a consolidação de seus usos modernos se deu entre os séculos XVII e XIX, quando da reconstrução da imagem que se tinha do ambiente, que deixou de ser repulsiva para ser cada vez mais atrativa, até se tornar lócus de novas formas de sociabilidade e de cuidados médicos e estéticos.

Não se trata de uma criação exclusiva da modernidade, pois a relação dos homens com o mar e com os diferentes ambientes litorâneos remonta à antiguidade. Corbin (1989) descreve com sensibilidade uma espécie de redescoberta, o desenvolvimento do desejo da beira-mar na aurora da modernidade. De ambiente inóspito, as praias foram se tornando, a partir do século XVII, em lugar de cuidado e lazer. Isso porque 0 próprio mar e/ou oceano, antes visto como bravio e habitado por feras gigantes, tornou-se objeto de curiosidade e maravilhamento. Ambos, as praias e o mar, deixaram de ser esse "território do vazio" para se tornarem um espaço purificador dos males do corpo e da alma.

No Brasil, a despeito da leitura segundo a qual o padrão colonizador teria legado uma ocupação majoritariamente litorânea, o que Moraes (2007) chama de "zona costeira" foi historicamente ocupado por algumas poucas cidades-porto, deixando vastas extensões semipovoadas ou desertas. Assim, a apropriação de suas praias se deu, sobretudo, no final do século XIX, quando as elites locais se voltaram para o mar, em um contexto de incorporação do que Dantas (2009) chamou de "práticas marítimas modernas" (banhos terapêuticos, vilegiatura etc.). Tais práticas foram aqui introduzidas como uma espécie de exclusivismo das elites locais, fiéis copiadoras dos hábitos ocidentais. Em alguns lugares, como o Rio de Janeiro e Recife, a incorporação desses hábitos foi o que ocasionou a ocidentalização das praias e sua balnearização, ao que foi precedido por uma apropriação muitas vezes violenta de um ambiente antes destinados apenas para as "práticas marítimas tradicionais" (pesca, defesa e atividade portuária).

O Rio de Janeiro, por exemplo, é uma cidade que alicerçou a identidade em torno de sua paisagem, especialmente a natural. $O$ ideal de uma cidade balneário introduzido pela construção da Avenida Beira-mar conjuminou com o que Ribeiro (2019) chamou de "desejo de paisagem", levando a uma série de 
transformações espaciais, de sociabilidades e de representações que perduram até os dias atuais. A apropriação das praias nesta cidade foi pioneira em todo o Brasil, pois correspondia ao seu maior centro de circulação de valores e hábitos sociais modernos-ocidentais no início do século XX. O Recife, por sua vez, também constituía um grande centro de circulação de valores no início desse século, e suas praias também foram apropriadas no arco de transformações espaciais, com sua própria versão da Avenida Beira-mar.

O importante aqui é perceber que a apropriação das praias, assim como os processos iniciais de valorização e consumo desses espaços, se deu, na grande maioria dos casos, vencendo-se uma série de inércias, muitas das quais correspondentes aos territórios residuais de populações autóctones (pescadores, quilombolas), com seus estilos de vida. Em todo o Brasil, as praias foram tomadas por classes sociais diferentes daquelas que lá viviam, seja pela obtenção de terras ou pela substituição dos objetos e fluxos geográficos preexistentes, ao que resultou em inúmeros conflitos. Neste sentido, pode-se dizer que a apropriação das praias neste país se deu em um contexto originário de espoliação, para que este ambiente pudesse se converter em vetor.

A primeira evidência de que as praias se tornaram efetivamente em vetores é o processo de valoração que thes acometeram no imediato de sua apropriação. Conforme as elites foram tomando as praias brasileiras, especialmente as nordestinas, esses ambientes passaram a ser mais procurados e tiveram seu valor acrescido apenas por conta de suas características 'originais'. A valoração, conforme esclarece Moraes (2007), é essa etapa essencial da própria valorização material do espaço, que ocorre quando é definido socialmente um valor para um dado lugar em razão de suas peculiaridades e potencial produtivo. Em geral, esse processo se dá mediante o surgimento e adesão de discursos justificadores do valor de um lugar em função de seus atributos frente aos demais lugares. Trata-se, portanto, de um valor comparativo. As praias passaram a ser objeto de discursos que engrandeciam tal ambiente frente a sua relativa escassez no contexto de todo território.

Depois de tomadas, as praias passaram a ser ocupadas primeiramente por segundas residências. No Brasil, a corrida pelas segundas residências se deu como um fenômeno inicialmente citadino, que foi perseguindo a linha de costa, espraiando-se para áreas não povoadas $\mathrm{E}$ isso fica ainda mais evidente para as cidades nordestinas, tais como Recife, que foi perdendo o vínculo fluvial e passou a crescer ao longo das praias depois do século XX. Segundo Dantas (2009), esse momento ocorre quando as cidades nordestinas deixaram de simplesmente encabeçar uma rede urbana que se voltava para o interior e passaram a vislumbrar "novos horizontes", uma espécie de "triunfo do mar" sobre o sentido do crescimento urbano. Em outras palavras, as praias firmavam-se como vetores, seja apontando o sentido da ocupação, ou fomentando o crescimento urbano em seu entorno. 
De ambiente semipovoado e destinado às práticas marítimas tradicionais, as praias foram apropriadas, valorizadas e tornadas objetos de disputas em pouco tempo. No caso das grandes cidades litorâneas do Nordeste, as praias passaram a indicar o lugar para onde seu espaço urbano se estenderia, incorporando áreas antes tidas como rurais e firmando o caminho por onde se foi constituindo crescentemente as metrópoles. Portanto, as regiões metropolitanas do Nordeste do Brasil devem muito de seu crescimento aos vetores praianos.

\section{ESPAÇO PRAIANO: DISCUSSÃO CONCEITUAL E CARATERÍSTICAS NO CONTEXTO BRASILEIRO}

A praia possui aqui uma dupla função: é um vetor para produção do espaço metropolitano, mas é também ambiente sobre o qual se produz o "espaço praiano". Isso significa dizer que, o lugar sobre o qual se estende um vetor na produção de um determinado espaço, muitas vezes, pode ser individualizado, com suas características e dinâmicas próprias. O espaço praiano é um entre vários espaços possíveis e deve ser estudado e planejado de maneira distinta dos demais espaços intra-metropolitanos.

A preferência por esse termo é mais uma entre tantas tentativas de aprimoramento terminológico que frequentemente precisamos realizar na Geografia. Sabe-se que, embora o espaço geográfico seja um só, porque a produção é cada vez mais uniforme, ele se apresenta de forma sempre diferenciada, pois depende das condições naturais e técnicas de cada local. Por isso, acreditamos que a adjetivação possui o importante papel de nos ajudar a entender a maneira diferencial com que essa produção homogênea se concretiza na superfície.

Essas adjetivações podem se basear em critérios naturais (como em espaço lagunar, fluvial, serrano, planáltico, semiárido etc.), populacionais (como em espaço feminino, negro, $\mathrm{LGBTQ}^{+}$, indígena etc.)2 econômico (produtivo, comercial etc.), regional (amazônico, nordestino, americano etc.) ou em mais de um ao mesmo tempo (ex.: espaço lagunar sulista, espaço produtivo amazônico etc.). Nenhum tipo é mais importante que outro, pois o que interessa é, a partir deles, estabelecer e compreender diferenças. Estas podem ser úteis em muitas ocasiões, mas devem ser usadas com desvelo, pois, lembremos, a produção é quase sempre uma só. Neste sentido, pode-se admitir didaticamente diversos espaço, mas todos eles constituem uma totalidade.

Conforme vimos advertindo, há diferenças conceituais entre "praia", "litoral", "costa" e "orla" que muitas vezes são negligenciadas. Muitos geógrafos, por puro descuido, incorrem a polissemias e confusões, em razão de não atentarem aos significados. Por exemplo, a confusão entre o que se entende por litoral faz com que se adjetive como "litorâneo" o que, em alguns casos, é apenas "praiano". O tradicional dicionário de

\footnotetext{
2 Neste caso, é preferível usar o termo território em vez de espaço, pois o que muitas vezes se busca designar é um processo de apropriação do espaço, muito mais que de produção.
} 
Guerra (1993), afirma que "litoral" diz respeito a um recorte amplo do território, correspondendo a toda "faixa de terra emersa", ao que engloba os diferentes contorno do relevo, isto é, desde as praias, até as falésias, arrecifes, deltas, fiordes etc. Por isso, o uso descomedido do adjetivo litorâneo pode diluir especificidades que precisam ser realçadas e que, em alguns casos, são essenciais para entender diferenças. Isto é, quando não se toma este cuidado, generaliza-se o entendimento de processos que deveriam ser vistos como específicos.

O termo "zona costeira" é mais um desses de definição imprecisa. Embora Guerra (1993) considere-0 equivalente a litoral, Suguio (1992) o define como uma extensão de terra variável que se estende desde a linha de praia até as principais mudanças nas feições morfológicas do relevo. Já Moraes (2007) afirma que a compartimentação natural não é suficiente para uma clara definição deste conceito e, por isso, seria preciso levar em conta critérios tomados da vida social, tais como as divisões político-administrativas e os padrões de ocupação.

O termo orla, segundo Muehe (2001), tem o significado semelhante ao de costa. Para este autor, que parte da Geomorfologia, a orla "diz respeito a estreita faixa de contato da terra com o mar na qual a ação dos processos costeiros se faz sentir de forma mais acentuada e potencialmente mais crítica" (MUEHE, 2001, p. 35). Contudo, este mesmo termo é socialmente empregado para designar tanto margens de rios e lagos, como de mares e oceanos. Não só isso, ele geralmente se refere aos trechos dessas margens que possuem equipamentos para o passeio, usufruto recreativo e turismo. Preferimos esse segundo entendimento, pois parece-nos que possui maior lastro social e político. Neste sentido, enquanto litoral e costa são amplos e dizem respeito a grandes recortes espaciais, a orla corresponde a um espaço menor e muito específico.

O termo praia, por sua vez, corresponde a "depósitos de areias acumuladas pelos agentes de transportes fluviais ou marinhos" (GUERRA, 1993), isto é, parcelas específicas do litoral, com características morfológicas distintas. Por isso é que o termo "praiano", segundo o Houaiss et al (2015), diz respeito àquilo que é "próprio da praia", que está "situado em praia, localizado à beira-mar". O ambiente da praia é o mais comum e mais acessível aos grupos humanos, estando muito mais presente em seu imaginário e em suas representações do litoral. Conforme demonstra Corbin (1989), o mundo moderno e ocidental assistiu a uma profunda mudança do significado social das praias, o que prova a importância desse ambiente específico para a consolidação de valores e comportamentos sociais. Portanto, foram as praias, e não todo o litoral, que se tornaram vetores do processo de metropolização durante o final do século XX. É por isso que preferimos o termo "espaço praiano", em vez de espaço litorâneo ou qualquer outro semelhante.

Este espaço possui suas peculiaridades. Ele é originalmente resultante de processos de espoliação, depois de uma profunda valorização e consumo, calcados na instalação de segundas residências e na atividade do turismo. Embora, no caso brasileiro, correspondam a um bem público de livre acesso, regido pela Lei $7661 / 88$ e pelo Decreto $5300 / 04$, as praias vêm sendo fortemente tomadas por essas duas 
atividades. A instalação de segundas residências surge na esteira do desenvolvimento da chamada "vilegiatura", isto é, da prática de estabelecer repouso em um lugar geralmente afastado dos centros urbanos, por motivos de saúde ou de férias. Hoje, a segunda residência também corresponde a um investimento, que pode também ser administrado por uma empresa de forma a garantir a sua rentabilidade (FONSECA e LIMA, 2012).

Segundo Dantas e Pereira (2010), essa tomada das praias pelos vilegiaturistas durante o século XX possuiu dois movimentos. Um primeiro, na primeira metade do século XX, caracterizado pela descoberta das praias, quando os pioneiros espoliaram as atividades que existiam nessas localidades e se estabeleceram, muitas vezes apoiados pela implantação de algumas infraestruturas, como avenidas, estradas e linhas de bonde que partiam dos centros urbanos. Depois, o segundo momento, ocorrido na segunda metade do século $X X$, é marcado pelo extrapolamento dos limites da cidade com a expansão da instalação de segundas residências e os vultosos investimentos estatais e privados em infraestruturas, algumas das quais turísticas.

O avanço das segundas residências, neste sentido, contribuiu à transformação do espaço praiano em mercadoria turística, pois preparou o terreno para a construção de infraestruturas voltadas ao desenvolvimento dessa atividade. Para tanto concorreram alguns investimentos públicos, especialmente aqueles advindos do Programa de Desenvolvimento do Turismo no Nordeste (PRODETUR). Criado no início da década de 1990, este programa objetivava: municiar as instituições Estaduais e Municipais de promoção do turismo; melhorar as condições infraestruturais urbanas dos principais destinos turísticos do Nordeste; revitalizar centros históricos e parques; ampliar e otimizar o ambiente de investimento turístico e; implantar infraestruturas rodoviárias e aeroviárias para o desenvolvimento do turismo.

A financeirização da economia e da atividade turística fez surgir grandes empreendimentos nesses espaços (ARAÚJO, 2011), alguns dos quais congregando diferentes serviços, como hotelaria, resort e segunda residência. Esses "empreendimentos turístico-imobiliários" acomodam parte do capital que circula na esfera produtiva e na financeira, aumentando sua intensidade exatamente nos momentos de superacumulação. Trata-se do que Harvey (1978) chamou de secondary circuit of capital, que se aproveita de oportunidades de investimentos em ofertas imobiliárias e, ao mesmo tempo, se beneficia de surtos especulativos.

Essa enorme massa de investimentos, nos grandes centro urbanos, também permitiu o surgimento de ofertas habitacionais auto-segregadas, seja em forma de loteamentos fechados ou em condomínio edilícios. A verticalização em praias de grandes cidades como Rio de Janeiro, Recife e Fortaleza transformou completamente a paisagem, que foi perdendo alguns de seus atributos originais. Em praias como a de Boa Viagem, no Recife, o crescimento populacional dos anos 1970/80 proporcionou a verticalização e o 
adensamento construtivo, tornando o bairro onde se localiza a referida praia no mais verticalizado de toda a cidade.

\section{OS VETORES PRAIANOS NA REGIÃO METROPOLITANA DO RECIFE (RMR)}

No Recife, a produção do espaço praiano e, consequentemente, a integração deste ao espaço metropolitano se deu no arco da incorporação das chamadas práticas marítimas modernas. Isto aconteceu quando as elites locais se voltaram para o mar, pondo em prática novos hábitos sociais advindos da Europa, tendo em vista o fato de que esta cidade funcionava, desde há muito tempo, como um centro de circulação de valores, gostos e hábitos sociais modernos. 0 primeiro e, talvez, mais importante hábito tenha sido o dos banhos de mar.

É preciso registrar que, anterior à chegada do hábito social dos banhos de mar, no Recife, há muito havia sido difundido um outro tipo de banho, o de rio. Assim como os de mar, o surgimento deste hábito se deu inicialmente como estratégia social de "fuga da cidade" para os arrabaldes, de modo a se livrar das epidemias e problemas socioambientais urbanos. Tratava-se também de um hábito tradicionalmente ligado às populações originárias, que o praticavam sem qualquer cerimônia.

Os rios que banham a cidade (notadamente o Capibaribe e o Beberibe) tiveram um papel basilar na consolidação de hábitos sociais e na própria constituição física do espaço urbano. Recife é uma cidade que se edificou no entorno de seus rios, tendo neles um vetor inicial e o principal meio de transporte até meados do século XIX. O próprio sítio geomorfológico onde historicamente se fundou o centro da cidade corresponde à foz conjunta de dois rios, atestando a referência fluvial desta cidade.

Até meados do século XIX, a cidade limitava-se ao atual centro, correspondendo aos bairros de Santo Antônio, São José e Boa Vista, bem como alguns nódulos "ganglionares" espalhados por toda a região plana a oeste, também chamada de "Várzea do Capibaribe". Muitos desses núcleos suburbanos surgiram no lugar dos antigos engenhos, alguns dos quais loteados pelas classes mais abastadas que lá se estabeleciam sazonalmente. Contudo, essa ocupação dos arrabaldes ocasionou, mais tarde, o processo de "democratização do subúrbio" (MELLO, 1992; ARAÚJO, 2007), cujo efeito foi solapar a paisagem verde, amena e sem ruídos que havia chamado a atenção dos primeiros habitantes. Apenas quando os subúrbios perderam o seu atrativo é que o mar e as praias entraram em cena.

Os banhos de mar e o processo de ocupação das praias já se encontrava em estágio mais avançado em cidades como o Rio de Janeiro, quando as elites recifenses e olindenses passaram a abandonar a resistência inicial e a cultuar mais este hábito. Para tanto, foram imprescindíveis a popularização dos conhecimentos relativos aos benefícios terapêuticos desses banhos e a chancela das autoridades médicas locais. A chegada do pensamento médico-higienista na metade dos oitocentos, mediante a criação de 
inúmeras juntas e organizações médicas, deram conjuntamente o peso científico para tais recomendações, seguindo descobertas e tratamentos elaborados na Europa.

Junto a difusão de um conjunto de hábitos sociais ligados ao cuidado e a exposição do corpo, bem como ao surgimento de novos padrões de beleza (ARAÚJO, 2007), as cidades de Olinda e Recife viram surgir as famosas casas de banho. A maior parte delas ajudaram a lançar um novo olhar para o mar, para as praias, e a vida ao ar livre. Aos poucos, o ambiente da praia foi sendo dotado de equipamentos e serviços para o usufruto balneário, tais como linhas de bonde e pontos de venda, bem como de residências. A praia deixava definitivamente de ser um lugar ermo ou "vazio".

Apesar disso, mesmo no início do século $X X$, as praias do Recife ainda eram lugares quase desabitados. Segundo Araújo (2007), quando se iniciou a busca pelos banhos de mar, o Recife não dispunha de boas praias para esta atividade e, por isso, Olinda recebia a maior parte dos banhistas. Havia outras praias muito mais distantes, ao sul do território municipal, sendo todas elas de difícil acesso. A região hoje correspondente aos bairros do Pina e Boa Viagem continha caminhos que eram tradicionalmente usados para o deslocamento em direção ao Sul da província, tais como a Recife and São Francisco Railway Company, estrada de ferro que ligava o Recife ao Rio São Francisco. Embora essenciais, essas estradas jamais serviram de vetor para o surgimento de núcleos de povoamento expressivos.

As casas de banhos que haviam possibilitado a balnearização pontual de trechos das praias de Olinda e Recife também não representavam vetores para um processo mais vertiginoso de valorização ao redor das praias, uma vez que 0 acesso a tais praias ainda era precário. Ainda nas primeiras décadas do século XX, diversos proprietários e empreendedores que haviam adquirido terras no entorno das praias passaram a pressionar o governo para a viabilização de um acesso desde a cidade até às praias localizado ao Sul. Foi, então, que surgiu o projeto para a construção da Avenida Beira-mar, desde o Pina até à Igreja de Boa Viagem, entre 1924 e 1926.

A Avenida Beira-mar foi construída a partir de um ambicioso conjunto de obras e um projeto dispendioso, que visava dotar toda a região de avenidas, ruas, água encanada, luz, saneamento e telefone. 0 objetivo era beneficiar o lugar de equipamentos e serviços urbanos necessários para torná-lo habitável, e capaz de receber serviços modernos e luxuosos. Na verdade, o projeto era só mais um entre um conjunto de outros projetos destinados à modernização e expansão urbana da cidade durante a década de 1920 (MOREIRA e SARAIVA, 2018), sendo responsável pela ulterior expansão para o sul do território, ao longo do setor oceânico. Somente depois de construída a Avenida é que as praias do Recife lograram constituir mais uma importante porção da cidade, sendo seus arredores transformados em bairros. Em outras palavras, ela permitiu a transformação da praia em vetor. 
Antes, porém, cabe registrar que as praias foram crescentemente apropriadas pelas elites locais e, em certo sentido, a Avenida foi construída em resposta a pressões destes mesmos grupos sociais. Devido a essa apropriação, esses ambientes tiveram seu valor acrescido, dado sua relativa escassez, peculiaridades ambientais e potencial produtivo. Eventos recreativos e atividades institucionais (temporadas de verão, concursos de beleza, campeonatos de automobilismo e motovelocidade, quermesses etc.) também contribuíram ao surgimento e adesão de discursos justificadores do aumento do valor do lugar.

Entre as décadas de 1920 e 1940, com avenidas, ruas planejadas e toda a infraestrutura necessária, os bairros adjacentes foram tomados por palacetes ecléticos e chalés. Depois, com a abertura de loteamentos, as áreas mais interiores foram ocupadas, o que permitiu o crescimento populacional. A partir da década de 1950, com a construção do novo aeroporto entre os bairros da Imbiribeira e do lbura, a atual zona Sul integrava-se ainda mais ao restante da cidade. Os bairros de Boa Viagem e Pina foram tomados por prédios modernos, atribuindo às praias o aspecto avançado e inovador existente até hoje. A oferta hoteleira cresceu enormemente, suplantando aos poucos a oferta da área central (SILVA, 2007). A partir de então, o ambiente paradisíaco e balneário da praia foi dando lugar a bairros residenciais cada vez mais consolidados, com ampla oferta de serviços, chegando a se tornar mais uma centralidade urbana.

Desde então, todo o setor oceânico passou a constituir um vetor de crescimento urbano e metropolização, que foi acompanhando as praias, espraiando-se para outros municípios e resultando em uma única mancha urbana conurbada e litorânea. Assim, durante o século $X X$, as praias passaram a indicar 0 lugar para onde o espaço urbano deveria se estender, incorporando mais este ambiente ao conjunto da cidade e, ao mesmo tempo, criando a partir dele o espaço metropolitano.

Esse movimento de crescimento partindo do Recife e acompanhando a linhas de praias se deu tanto no sentido Norte, como no Sul (Figura 1). Ao Norte, o crescimento se deu através: da apropriação das praias dos municípios de Olinda (Bairro Novo, Casa Caiada e Rio Doce) e Paulista (Janga, Pau Amarelo e Maria Farinha); da valorização dessas praias mediante construção de segundas residências e da atividade turística; bem como de loteamentos e constituição de novos bairros. Ao Sul, o mesmo processo permitiu a incorporação das praias do município de Jaboatão dos Guararapes, tais como as de Piedade, Candeias e Barra de Jangada, formando bairros homônimos. O processo de surgimento de Piedade e Candeias, contudo, se deu como uma espécie de extensão da formação do bairro de Boa Viagem, no Recife, em um movimento quase idêntico de apropriação e valorização fortemente calcado no provimento de infraestruturas viárias e na apropriação pelas elites. 


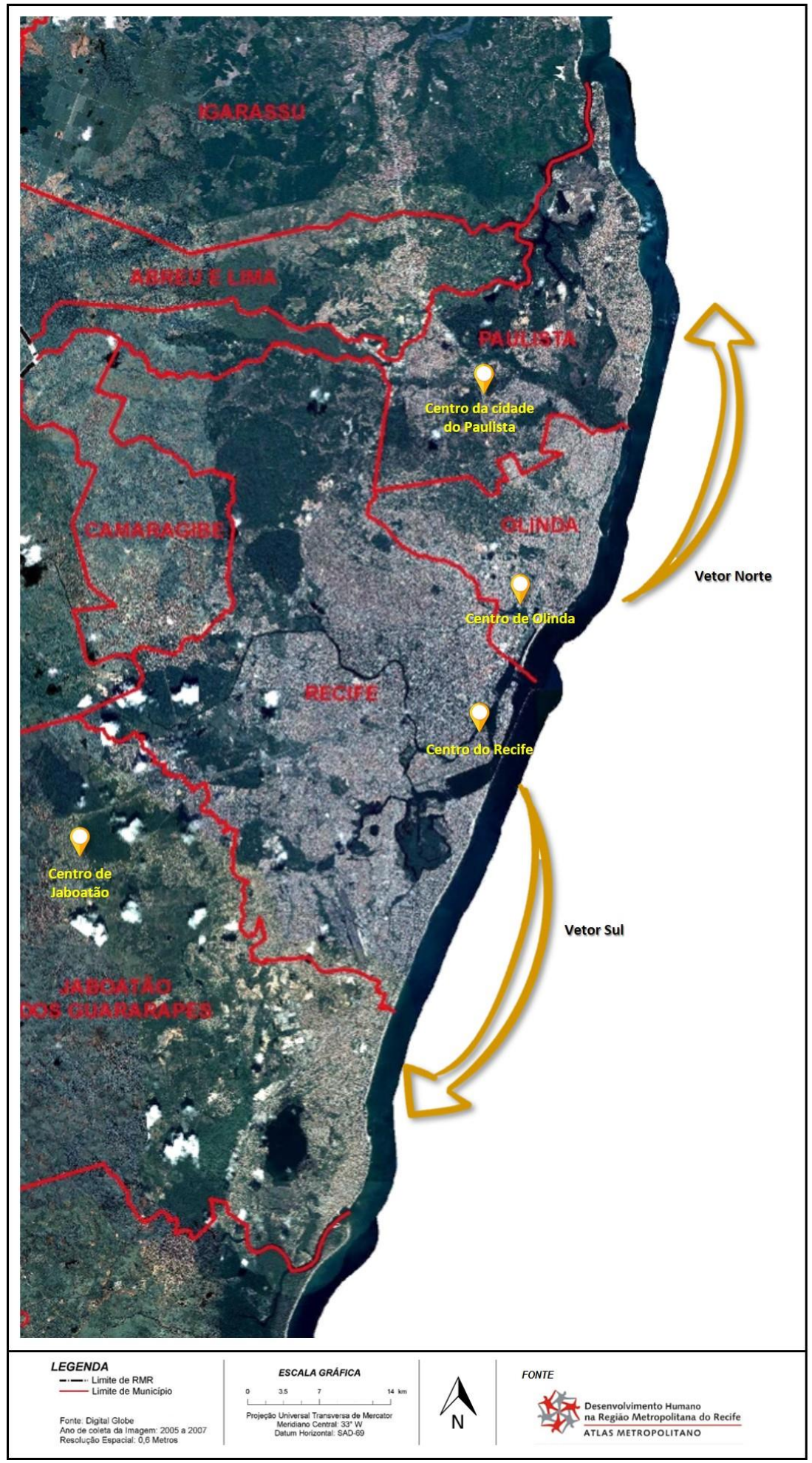

Figura 1 - Trecho da Região Metropolitana do Recife com localização aproximada dos centros das quatro principais cidades e o sentido dos vetores praianos de crescimento metropolitano

Fonte: Atlas de Desenvolvimento Humano da Região Metropolitana do Recife, 2015; Edição: o autor, 2020.

A importância dos vetores praianos (seja Norte ou Sul) é tamanha que contribuiu para a alta integração desses quatro municípios metropolitanos: Paulista, Olinda, e Jaboatão dos Guararapes. Eles 
integram junto com Recife o núcleo principal da região metropolitana, formando um único tecido urbano conurbado, com alta integração funcional e grande fluxo pendular de trabalhadores (Figura 2).

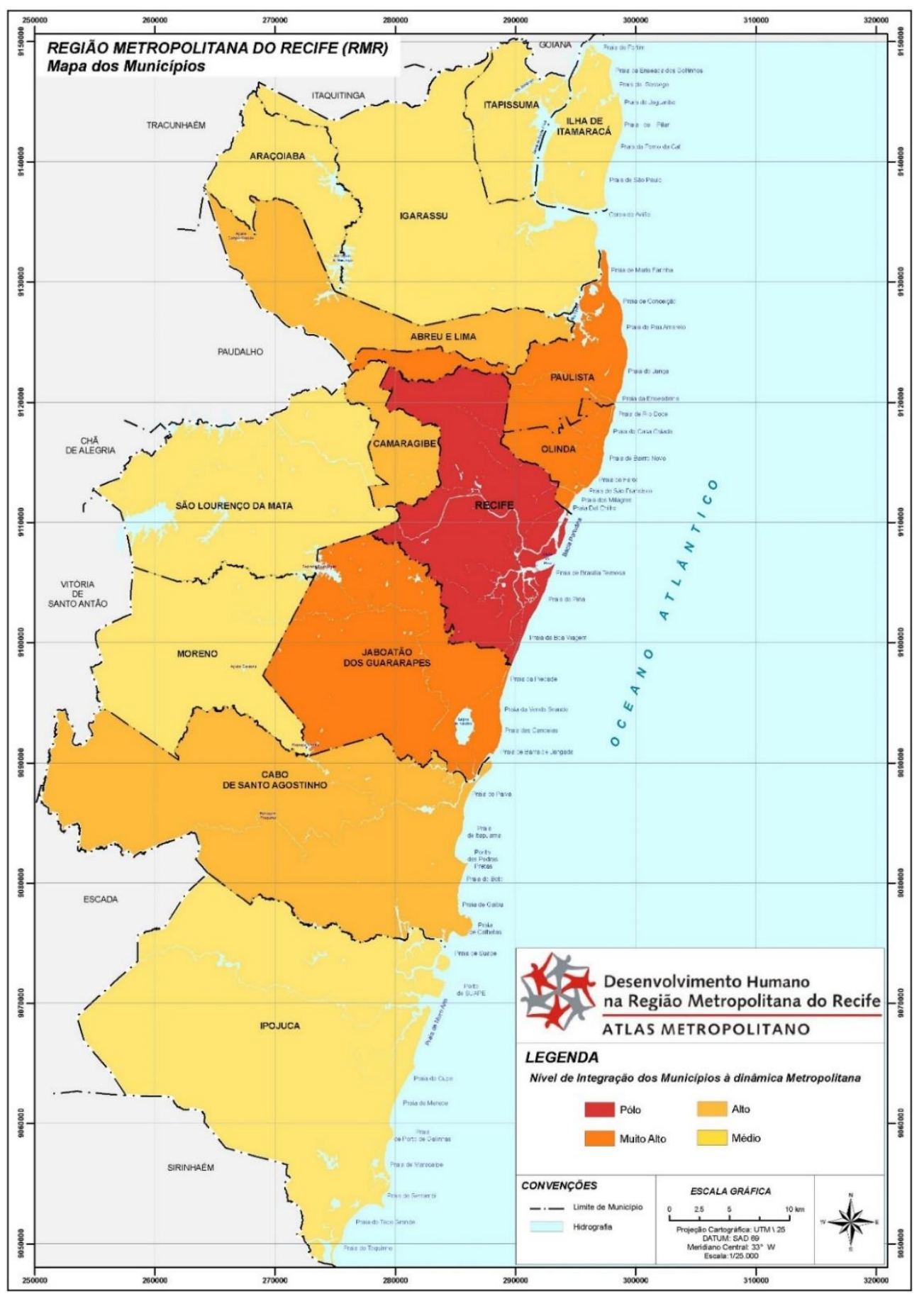

Figura 1 - Municípios que constituem a Região Metropolitana do Recife com indicação do nível de integração à dinâmica Metropolitana

Fonte: Atlas de Desenvolvimento Humano da Região Metropolitana do Recife, 2015 
O vetor Norte segue desde o centro da cidade de Olinda, passando pelas praias do Farol, Bairro Novo, Casa Caiada e Rio Doce, no município de Olinda, constituindo bairros homônimos. Em seguida, continua pelas praias do Janga, Pau Amarelo, Conceição e Maria Farinha, no município de Paulista, formando os bairros do Janga, Pau Amarelo, Nossa Senhora do Ó, Nossa Senhora da Conceição e Maria Farinha. Corresponde a um trecho com aproximadamente 162 mil habitantes ${ }^{3}$, segundo o último censo do Instituto Brasileiro de Geografia e Estatística (IBGE, 2010), que foi se estabelecendo desde a área mais consolidada (o centro de Olinda, junto com os bairros de Santa Tereza, Varadouro e Carmo) em direção ao Norte, ocupando e valorizando áreas antes "desocupadas", chegando até a foz do Rio Timbó. Mais adiante, tem-se as praias de Nova Cruz e Capitão, bem como a ilhota de Coroa do Avião, em Igarassu, e as praias do Forte, Pilar, Jaguaribe e Sossego, em Itamaracá. Apesar de densamente povoadas, trata-se de praias mais afastadas do núcleo metropolitano e com menor presença de atividades turísticas.

A apropriação ao longo desse vetor foi majoritariamente voltada ao estabelecimento de segundas residências, muitas das quais concebidas em pequenos enclaves autosegregados, em forma de "privês". Em alguns trechos, esse tipo de ocupação espoliou formas mais antigas, desenvolvidas por populações de pescadores e antigos habitantes. A área possui também construções antigas, muitas das quais tombadas pelas instituições de memória, tais como o Forte de Nossa Senhora dos Prazeres do Pau Amarelo, o conjunto arquitetônico da Igreja de Senhora do Ó, além da Igreja de Nossa Senhora da Conceição. Também foi objeto de algumas promoções habitacionais de ordem pública e privada, através de loteamentos. Hoje, especialmente no bairro de Maria Farinha, além da presença de hotéis e marinas, a área se destaca pela existência de atividades relacionadas ao lazer (como o parque aquático Veneza Water Park) e aos esportes de zona de praia (canoagem, stand up paddle, vela e passeios de barcos motorizados).

O vetor Sul segue desde os arrecifes de corais que cercam o Porto do Recife, passando pela bacia do Pina, Brasília Teimosa, as praias do Pina e Boa Viagem, bem como Piedade, Candeias e Barra de Jangada, em Jaboatão dos Guararapes, criando bairros homônimos. Todo o vetor corresponde a uma área com aproximadamente 336 mil habitantes ${ }^{4}$, segundo censo do IBGE. Portanto, quase o dobro do contingente existente ao longo do vetor norte, mostrando a importância desempenhada pelo processo de ocupação, por parte das elites recifenses, das praias ao Sul do território municipal.

\footnotetext{
${ }^{3}$ Cálculo feito a partir da soma do contingente populacional dos bairros praianos dos municípios de Olinda e Paulista. 0 número pode ser um pouco menor se considerarmos que parte do bairro de Rio Doce, em Olinda, situa-se mais adentro do território municipal, não tendo sido constituído por dinâmicas diretamente ligadas à produção do espaço praiano. Por outro, esse número pode ser maior se considerarmos Poty, Engenho Maranguape, Parque do Janga e Jardim Maranguape, em Paulista, bairros que podem ter sua dinâmica populacional de alguma forma relacionadas com a produção do espaço praiano.

${ }^{4}$ Mais uma vez consideramos apenas a população absoluta existente nos bairros praianos. Neste caso, contudo, o contingente pode ser um pouco maior, pois muitos outros bairros situados um pouco mais adentro dos territórios municipais tiveram sua dinâmica de crescimento populacional direta ou indiretamente relacionados com a produção do espaço praiano. São os casos de Setúbal e Imbiribeira no Recife, e Porta Larga e Prazeres, em Jaboatão dos Guararapes.
} 
A apropriação e valorização ao longo desse vetor se deu de forma muito semelhante ao supramencionado processo de produção do espaço praiano recifense. Isto é, por uma ocupação pelas elites e uma valorização alicerçada no provimento de infraestruturas viárias. Primeiro, a produção se deu através de segundas residências, depois por meio residências definitivas e pelo estabelecimento de redes hoteleiras e atividades turísticas, chegando a constituir uma centralidade. Pode-se, inclusive, considerar a maior parte desse vetor como uma extensa centralidade urbana, congregando a maioria dos serviços especializados da metrópole, três shopping centers e algumas das maiores e mais movimentadas vias urbanas metropolitanas. Trata-se também de um trecho marcado por forte verticalização e pela existência de uma miríade de tipologias habitacionais auto-segregadas, compondo um cenário de forte fragmentação.

Os dois vetores comportam ainda as mais profundas desigualdades metropolitanas. O vetor Sul, em especial, possui as desigualdades mais escandalosas, pois apresenta, por vezes em um mesmo bairro, condomínios de luxo ao lado de palafitas. Conforme exposto em Santos (2020), essa coexistência entre a opulência das habitações luxuosas e a pobreza extrema muitas vezes finda em conflitos sociais e violência, para cuja resposta do Estado quase sempre visa reproduzir preconceitos. O resultado é o tratamento militarizado de mais esse problema urbano, muitas vezes traduzido em policiamento ostensivo e prisões arbitrárias. Nesse mesmo viés, o Estado muitas vezes consente ao surgimento de respostas individuais e paramilitares ao problema da violência, mediante a ação de grupos de segurança independentes e redes de proteção e segurança privados.

Hoje, esse processo de produção do espaço seguindo o vetor Sul já extrapola os limites dos municípios que compõem o núcleo metropolitano e aponta para a incorporação de novas áreas, cada vez mais ao Sul, como as praias do município do Cabo de Santo Agostinho. Dois grandes polos, o megaprojeto imobiliário Reserva do Paiva e o Complexo Portuário de Suape, podem ser os responsáveis por essa espécie de alongamento deste vetor, que pode vir a estender ainda mais o processo de metropolização em direção ao litoral Sul do Estado. Os empreendimentos da praia do Paiva e os loteamentos nas praias de Itapuama e Pedra do Xaréu já se ligam à núcleos de ocupação mais antigos, como os das praias de Enseada dos Corais e Gaibú, passando por Calheitas até Suape. A expectativa é a de que essas áreas constituam, em um futuro muito próximo, espaços onde se realizarão profundos processos de valorização e consumo do espaço.

O suposto alongamento do vetor Sul pode estar acontecendo a despeito da tendência atual, que é a da reprodução do espaço. Para alguns autores, a valorização verificada para além deste vetor tem por referência as praias, para outros são apenas os dois polos supracitados. Mais importante é perceber o que ela comprova: a despeito da tendência à reprodução, novos vetores expansivos podem sempre surgir, sejam praianos ou não. 


\section{CONCLUSÕES}

Os vetores indicam a direção adquirida pelo processo de valorização expansiva do espaço, mas também podem ser formas espaciais que atraem e possibilitam essa valorização. Na realidade urbana brasileira, as praias muitas vezes funcionam como vetores do processo de crescimento das cidades, apontando a direção desse crescimento e fomentando o permanente processo de valorização e consumo.

O espaço praiano é aquele resultante de processos de espoliação, valorização e consumo, muitas vezes calcados na instalação de segundas residências e na atividade do turismo. Tal espaço possui uma série de especificidades e é apenas um entre vários espaços intra-metropolitanos possíveis. Assim, as praias são, ao mesmo tempo, ambientes sobre o quais se produz o espaço praiano e vetores para produção do espaço metropolitano

No caso do Recife, desde o início do século XX, as praias têm sido o ambiente por onde a cidade vem crescendo, interligando-se com outros núcleos urbanos e, consequentemente, criando sua região metropolitana. Essa urbanização praiana tende a partir desde as áreas mais consolidadas até as áreas menos ocupadas do território metropolitano, seguindo tendência já destacada por Dantas e Pereira (2010) em estudo sobre as principais regiões metropolitanas do Nordeste.

O núcleo metropolitano da RMR, atualmente constituído pelos municípios do Recife, Olinda, Paulista e Jaboatão dos Guararapes, possuem o atual grau de integração em termos de dinâmica metropolitana, em parte, porque possuem um único tecido urbano, que se estende justamente ao longo de suas praias.

Há, contudo, um suposto alongamento do vetor Sul, que não se sabe ao certo se ainda é praiano ou se está relacionado apenas aos dois maiores empreendimentos do Sul metropolitano (Reserva do Paiva e o Porto de Suape). Nossa aposta é a de que ambos, as praias e os empreendimentos, são os responsáveis. Porém, uma resposta mais assertiva a essa questão requer novos estudos.

\section{REFERÊNCIAS}

Araujo, C. P. (2011) Terra à vista! O litoral brasileiro na mira dos empreendimentos turísticos imobiliários. 2011. Tese de Doutorado - Universidade de São Paulo, Programa de Pós-graduação em Arquitetura e Urbanismo, São Paulo

Araújo, R. C. B. (2007) As praias e os dias: história social das praias do Recife e de Olinda. Recife: Fundação de Cultura Cidade do Recife Corbin, A. (1989) Território do vazio: a praia e o imaginário ocidental. São Paulo: Companhia das Letras.
Dantas, E. W. (2009) Maritimidade nos trópicos: por uma geografia do litoral. Fortaleza: Edições UFC

Dantas, E. W. C; Pereira, A. Q. (2010) Reflexões sobre a vilegiatura marítima nos trópicos. In: Eustógio W. C. Dantas et al (Eds.). Turismo e imobiliário nas metrópoles. Rio de Janeiro: Letra Capital, p. 71-83

Fonseca, M. A. P; Lima, R. M. M. (2012) Segunda residência: conceito, características e significados. In: M. Aparecida Fonseca (Eds.) Segunda residência, lazer e turismo. Natal: Editora UFRN, p. 11-18. 
Guerra, A. T. (1993) Dicionário geológicogeomorfológico. 8.ed. Rio de Janeiro: IBGE

Houaiss, A; Villar, M. S; Franco, F. M. M. (2015) Pequeno dicionário Houaiss da língua portuguesa. São Paulo: Moderna.

Harvey, D. (1978) The urban process under capitalism: a framework for analysis. International journal of urban and regional research, v. 2 (1-4), p. 101-131.

Mello, E. C. Canoas do Recife. (1992) In: M. Souto Maior; L. D. Silva (Eds.) O Recife: quatro séculos de sua paisagem. Recife: Massangana, p. 193-225.

Moraes, A. C. R. (2007) Contribuição para a gestão da zona costeira do Brasil: elementos para uma Geografia do litoral brasileiro. São Paulo: Annablume

Moreira, F. D; Saraiva, K. (2018) Dos subúrbios coloridos aos horizontes molhados: a expansão urbana do Recife nos anos 1920. In: Anais do XV Seminário de História da Cidade e do Urbanismo. Rio de Janeiro: UFRJ.

Muehe, D. (2001) Critérios morfodinâmicos para o estabelecimento de limites da orla costeira para fins de gerenciamento. Revista Brasileira de Geomorfologia, v. 2 (1), p. 35-44.

Ribeiro, R. W. (2019) Rio de Janeiro e a Avenida Beira Mar: desejo de paisagem e cidade balneário nas primeiras décadas do século XX. Confins (Paris), v. 1, p. 6.

Santos, O. A. A. (2020) A fragmentação do espaço no Recife. Recife: Ed. UFRPE

Santos, O. A. A. (2019) Considerações sobre a produção do espaço praiano no Recife: os limites e os desafios do planejamento urbano. In: Anais do XVI SIMPURB. Vitória: UFES, p. 2259-2278.

Silva, A. M. P. (2007) O processo de reorganização espacial da hotelaria do Recife: concentração em Boa Viagem e marginalização da área central. Dissertação (Mestrado)- Universidade Federal de Pernambuco, Programa de Pós-graduação em Geografia, Recife

Suguio, K. (1992) Dicionário de Geologia Marinha. São Paulo: T.A. Queiroz 